\title{
Mortality of workers at acetylene production plants
}

\author{
M L NEWHOUSE, G MATTHEWS, K SHEIKH, K L KNIGHT, D OAKES, \\ K R SULLIVAN \\ From the Department of Occupational Health, London School of Hygiene and Tropical Medicine, London \\ WCIE 7HT, UK
}

\begin{abstract}
To reduce the risk of explosion oxyacetylene cylinders are filled with a spongy mass, acetone is added to saturate the mass, and acetylene is pumped into the cylinder. The first cylinders manufactured before 1936 used a kapok filling topped off with about 16 oz of crocidolite asbestos, with a metal gauze thimble inserted to reduce risk of flash back. Cylinders must be examined annually. The use of crocidolite ceased in 1972 and other fillings have been adopted since 1970; kapok cylinders now constitute less than $5 \%$ of the total stock. To assess possible hazards, a mortality study of workers first employed between 1935 and 1975 and followed up to December 1984 was undertaken. Simulation tests showed low concentrations of asbestos in the air even in the earliest period. The population studied consisted of 370 workers at the Bilston plant in the West Midlands, 611 at the 14 other plants in England and Wales, and 120 in Scotland. No deaths occurred from mesothelial tumours but there was an excess of deaths from cancer, particularly lung cancer, cancer of the stomach, and cancer of the pancreas, the latter accounting for eight deaths. Risks appeared to be concentrated at the Bilston plant. The importance of these findings is discussed.
\end{abstract}

Acetylene gas is used primarily for welding and cutting, usually with oxygen for oxyacetylene welding. It is supplied in cylinders known as dissolved acetylene (DA) cylinders. Acetylene is an explosive gas and is soluble in acetone. To reduce the risk of explosion, the DA cylinder is filled with a porous mass into which acetone is added to saturate the mass. Acetylene is then slowly pumped into the cylinder. The composition of the mass has changed over the years. At present three types are used in the United Kingdom. The first cylinders manufactured before 1936 used a kapok filling that was topped off with about $16 \mathrm{oz}$ of crocidolite asbestos rammed into the cylinder neck. A metal gauze thimble was inserted at the neck of the cylinder to reduce risk of flash back. Charcoal was introduced as the filling in 1936 and manufacture continued until 1968. Cylinders with charcoal filling still constitute a high proportion of total stock and contain no asbestos. "Monolithic mass" cylinders were introduced in 1969 and are the current design. The mass is calcium silicate containing charcoal and chrysotile asbestos. The ingredients are mixed to a thick slurry with water and then placed into empty cylinder shells. The mass sets hard like pumice; there is no free asbestos.

Accepted 2 March 1987
By the late 1970s the stock of kapok cylinders was less than $10 \%$ of all cylinders in circulation. Kapok cylinders at present account for less than $5 \%$ of the total DA cylinder stock.

DA cylinders had to be examined by law annually to ensure that the mass was in sound condition. The methods of examining kapok cylinders varied between three successive periods. During the first period, which lasted from the time of first manufacture up to about 1939, the thimble and blue asbestos were removed and the kapok examined; about $16 \mathrm{oz}$ of asbestos and the thimble were then replaced. The second period was between 1939 and 1972. Owing to settling of the cylinder packing the practice was to remove the thimble, top up with a small amount of asbestos if necessary, without removing the old asbestos, and then to replace the thimble and valve. A search for a material to replace crocidolite asbestos began in 1969. Sisal was finally chosen and since January 1972 has been put over the crocidolite as required. All topping up with crocidolite ceased and stores of crocidolite asbestos were disposed of. Between 1972 and 1975 no removal of any material took place.

In 1975 and 1976 the metal thimbles were replaced with felt plug filters and every kapok cylinder examined had a thick pad of sisal put over the crocidolite. 
Before removal of the cylinder valve $8 \mathrm{oz}$ of acetone were poured into the cylinder. Using approved face masks, the cylinder was devalved and the thimble removed and sealed into a polythene bag before appropriate disposal. Sisal was added and a felt pad sandwiched between wire gauze discs was inserted in place of the thimble.

Nearly all the kapok cylinders were treated in this way. Since 1976, any kapok cylinder observed during its inspection to have a metal thimble in place has generally been left undisturbed, the valve replaced, and the cylinder sent to a central point for sealing and disposal.

\section{Investigations of possible health effects of exposure to crocidolite asbestos in kapok cylinders}

In July 1975 concern was expressed about the possible effects on health of the past exposure to crocidolite asbestos while examining the kapok cylinders. As use of crocidolite asbestos in acetyline cylinders dated back to 1930 or earlier, examination of the causes of death of all workers employed at these factories appeared to be an appropriate method of estimating whether an excess of deaths from a particular cancer could be attributed to an occupational exposure.

\section{Methods}

\section{SIMULATION TESTS}

A site was selected to provide the essential facilities for a programme of tests designed to simulate the procedures undertaken for the three types of operation described above. The sampling procedure provided that the predictably least dusty jobs were done first to prevent interfering contamination of the workspace. Each type of operation was repeated three times: for each a personal sample was collected. Air samples were taken at static locations before the personal samples were taken; these were then repeated during the test cycles and also later when the programme of tests had been completed.

Air samples were collected using personal sampling pumps to draw air at a flow rate of one litre per minute through filters $0.8 \mu \mathrm{m}$ pore size contained within plastic open face filter holders; the filter holders were mounted on the left shoulder of the worker concerned. Flow rate was monitored at the beginning and end of each sample sequence with a flow meter of appropriate range. The sample filters were returned to the laboratory, mounted on slides and cleared with triacetin, and counted in accordance with ARC technical note No $1 .^{1}$

MORTALITY STUDY

DA plants where cylinder inspection takes place are scattered throughout the country. The largest and one of the oldest plants was at Bilston in the West Midlands. The Bilston plant was thought to have a complete set of records of past employees and it was decided to make a pilot study of these records. Preliminary analysis suggested that the only unusual finding was an unexpectedly high mortality from cancer of the pancreas. As numbers were small it was decided to extend the study to cover all plants where records of past employees were available. In 1978 records were obtained from 14 plants in England and Wales, four in Scotland, and one in Northern Ireland (table 1). Only two plants had no records of their past employees. The northern Irish group of 23 past and present workers was not included in the study.

The date of birth, name, dates of employment, and jobs of the workers whose employment for at least one shift started between 1935 and 1976 were abstracted from company records. It was seldom possible to ascertain previous occupations. These records were sent to the Central Registrar of the National Health Service of the Office of Population Censuses and Surveys, where the individual was identified alive or dead. If dead a copy of the death certificate was supplied. If searches there were unsuccessful the record was forwarded to the Central Insurance Registry of the Department of Health and Social Security where a similar search was performed. Deaths occurring between 1 January 1935 and 31 December 1984 were included in the study.

The observed mortality was compared with that ex-

Table 1 Employees for whom records were retrieved, by plant

\begin{tabular}{lc} 
& No of employees \\
\hline & \\
\hline Northern region: & 17 \\
Dundee* & 99 \\
Polmadie (Glasgow) & 4 \\
Govan (Glasgow)* & 4 \\
Hillington (Glasgow)* & \\
Southern region: & 35 \\
Bristol & 60 \\
Cricklewood* & 37 \\
Hackney (London)* & 27 \\
Ipswich & 16 \\
Poplar (London)* & \\
Southampton* & 66 \\
Eastern region: & 121 \\
Chester-le-Street & 75 \\
Derby & 13 \\
Leeds* & 372 \\
Tinsley (Sheffield)* & 59 \\
Western region: & - \\
Bilston** & 111 \\
Cardiff* & 23 \\
Crewe* & \\
Worsley & \\
Northern Ireland: & \\
Belfast & \\
\hline *Plants closed. & \\
&
\end{tabular}


Table 2 Mortality of DA workers at Bilston and other plants in the United Kingdom showing effect of regional adjustment at Bilston

\begin{tabular}{|c|c|c|c|c|c|c|c|c|}
\hline & \multicolumn{5}{|c|}{ Bilston $(n=370$, man-years $=8901)$} & \multicolumn{3}{|c|}{ Other plants $(n=611$, man-years $=12546)$} \\
\hline & \multicolumn{3}{|c|}{ England and Wales } & \multicolumn{2}{|c|}{ Regional adjustment } & \multirow[b]{2}{*}{ Obs } & \multirow[b]{2}{*}{$\operatorname{Exp}$} & \multirow[b]{2}{*}{$S M R$} \\
\hline & Obs & $\operatorname{Exp}$ & $S M R$ & $\operatorname{Exp}$ & $S M R$ & & & \\
\hline $\begin{array}{l}\text { All causes } \\
\text { Bronchitis } \\
\text { Pneumonia } \\
\text { All cancers } \\
\text { Cancer of lung } \\
\text { Cancer of pancreas } \\
\text { Cancer of stomach }\end{array}$ & $\begin{array}{r}129 \\
11 \\
13 \\
47 \\
18 \\
6 \\
8\end{array}$ & $\begin{array}{r}119 \cdot 1 \\
8 \cdot 4 \\
6 \cdot 0 \\
29 \cdot 5 \\
12 \cdot 1 \\
1 \cdot 2 \\
3 \cdot 5\end{array}$ & $\begin{array}{l}108 \\
131 \\
217^{* *} \\
159^{* *} \\
149 \\
493^{* *} \\
231^{*}\end{array}$ & $\begin{array}{r}128 \cdot 6 \\
10 \cdot 6 \\
8 \cdot 3 \\
32 \cdot 5 \\
13 \cdot 6 \\
1 \cdot 3 \\
3 \cdot 9\end{array}$ & $\begin{array}{l}100 \\
104 \\
157 \\
145^{* *} \\
132 \\
470^{* *} \\
207^{*}\end{array}$ & $\begin{array}{r}96 \\
5 \\
6 \\
41 \\
15 \\
2 \\
7\end{array}$ & $\begin{array}{r}114 \cdot 7 \\
6 \cdot 8 \\
4 \cdot 8 \\
29 \cdot 9 \\
12 \cdot 5 \\
1 \cdot 2 \\
3 \cdot 2\end{array}$ & $\begin{array}{l}84 \\
73 \\
124 \\
137 \\
120 \\
160 \\
220^{*}\end{array}$ \\
\hline
\end{tabular}

${ }^{*} p<0.05 ;{ }^{* *} p<0.01$

pected based on sex, age, and period specificity using the subject years method. ${ }^{2}$ The untraced men were excluded from the study. For all plants in England and Wales except Bilston the death rates for England and Wales were used. The rates for Scotland were used for the Scottish DA plant. Bilston lies within the West Midlands conurbation where Acheson and Gardner have shown some excess cancer mortality. ${ }^{3}$ Expected rates were therefore calculated using these area mortality tables. ${ }^{4}$ The standardised mortality ratios at Bilston using national rates and regional rates were compared (table 2).

The SMR for all causes is reduced from 108 to 100 and for all cancers from 159 to 145 . The SMR although still raised is also considerably reduced for pneumonia. For the subsequent tables, the regional adjustment is used where the the SMR for the Bilston plant is calculated.

As the latent period for asbestos related cancers is generally 20 years or longer the follow up period was divided into two periods, the first up to 20 years since first entering employment and the second 20 years or longer. Only those men first employed before 1965 could contribute to the second period of follow up. An analysis of the effect of duration of service was also made on this group.

Cylinder examiners were the particular workmen

Table 3 Time weighted average concentration of fibres in air: British Oxygen Company simulation tests

2 November 1976

\begin{tabular}{lll}
\hline \multicolumn{2}{l}{ Conditions at: } & Concentration $($ fibres $/$ ml) \\
\hline $1936-39$ & Run 1 & $0 \cdot 50$ \\
& Run 2 & $0 \cdot 85$ \\
$1939-72$ & Run 1 & $0 \cdot 25$ \\
& Run 2 & 0.38 \\
& Run 3 & 0.33 \\
$1972-75$ & Run 1 & 0.02 \\
& Run 2 & 0.03 \\
& Run 3 & 0.09 \\
\hline
\end{tabular}

who handled crocidolite asbestos, although labourers in cylinder repair shops and some storemen may have had contact. The cylinder examiners were identified through the job histories on their personnel cards and their mortality was examined separately. Their follow up started on their first day of employment as a cylinder examiner. Many of these men had also worked in other jobs; the risks, if any, for cylinder examiners and for other jobs cannot be fully separated.

\section{Results}

\section{SIMULATION TESTS}

The concentrations derived from analysis of the collected samples are shown in table 3 in the reverse order from which they were collected. They show a shift in measured concentrations clearly linked to a reduction in contact with asbestos that is consistent with the changes in procedure that occurred over the years.

The additional component of the task common to the job up to 1972 was that of transferring from a bulk supply of raw fibre to a box on the work bench a sufficient supply for the job in hand. This was evaluated as part of the sampling programme. The contribution made by this particular job to the airborne fibre concentrations has been estimated. While in isolation the measured fibre concentrations were high $(10.4 \mathrm{f} / \mathrm{ml})$, because of the short duration (some 30 minutes a week), the effect on the weekly averaged concentration was negligible. The results shown are time weighted average concentrations incorporating the transfer component.

\section{MORTALITY STUDY}

Table 4 shows the current status of the population. The Bilston population is older than the population in other plants in England and Wales (table 5); $35 \%$ of workers at Bilston are now dead compared with $15.5 \%$ at the other plants.

The mortality for all causes and certain selected causes at Bilston and for the other 14 plants com- 
Table 4 Study population: entering 1935-76

\begin{tabular}{lllcrr}
\hline & Bilston & $\begin{array}{l}\text { Other } \\
\text { England and Wales }\end{array}$ & Scotland & N Ireland & Total \\
\hline Alive & 241 & 505 & 90 & 21 & 857 \\
Emigrated & -2 & 10 & 4 & 2 & 14 \\
No trace & 129 & 96 & 22 & - & 21 \\
Dead & 372 & 620 & 124 & 23 & 1139 \\
Total & & 96 & 8 \\
\hline
\end{tabular}

Table 5 Age distribution of workers at Bilston and other plants in England and Wales

\begin{tabular}{lcl}
\hline Date of birth & $\begin{array}{l}\text { Bilston } \\
(\%)\end{array}$ & $\begin{array}{l}\text { Other plants } \\
(\%)\end{array}$ \\
\hline$<1900$ & $9 \cdot 2$ & $1 \cdot 1$ \\
$1900-24$ & $45 \cdot 9$ & $33 \cdot 6$ \\
$1925-50$ & $44 \cdot 9$ & $65 \cdot 3$ \\
Mean date of birth & 1920 & 1929 \\
\hline
\end{tabular}

bined is shown in table 2. The most pronounced excess is observed at Bilston for carcinoma of the pancreas; "all cancers," cancer of the stomach as well as cancer of the pancreas also show statistically raised SMRs even when using the regional figures. The SMR for cancer of the lung is not significantly raised. The excess of deaths due to non-malignant respiratory disease is not significantly raised above the regional level. At the other plants in England and Wales there were two deaths from cancer of the pancreas with $1 \cdot 2$ expected, SMR 160, but not a significant excess. There were seven deaths from cancer of the stomach with 3.2 expected, a statistically significant increase.

The analysis was repeated for the causes of death of interest according to the duration of follow up (table
6). At Bilston the SMR was significantly raised for all cancers and for cancer of the pancreas with five of the six deaths occurring in those with a follow up of over 20 years. For cancer of the lung, 16 of the 18 deaths occurred in men with long follow up, making this now a significant excess. Five of the eight deaths from cancer of the stomach were among men with the shorter follow up period and the SMR 267.9 was significantly raised.

At the other plants, although the SMR for lung cancer was raised to 145 in the group with longer follow up, this was not statistically significant. For cancer of the pancreas, there was one death in each group with appreciably raised SMRs but not reaching statistical significance. Of the seven deaths from cancer of the stomach, five were among men with less than 20 years follow up.

The analysis was repeated for the small group (110) of men who had ever worked as cylinder examiners (table 7). At Bilston two of the 18 workers with 20 years or longer follow up died of cancer of the pancreas; there was also an appreciably raised SMR for lung cancer. There were no deaths from cancer of the stomach in this group at Bilston or the other plants.

For the long follow up group the duration of service was divided into five year periods. For the $0-5$

Table 6 Mortality of all workers at Bilston and other plants by duration of follow up

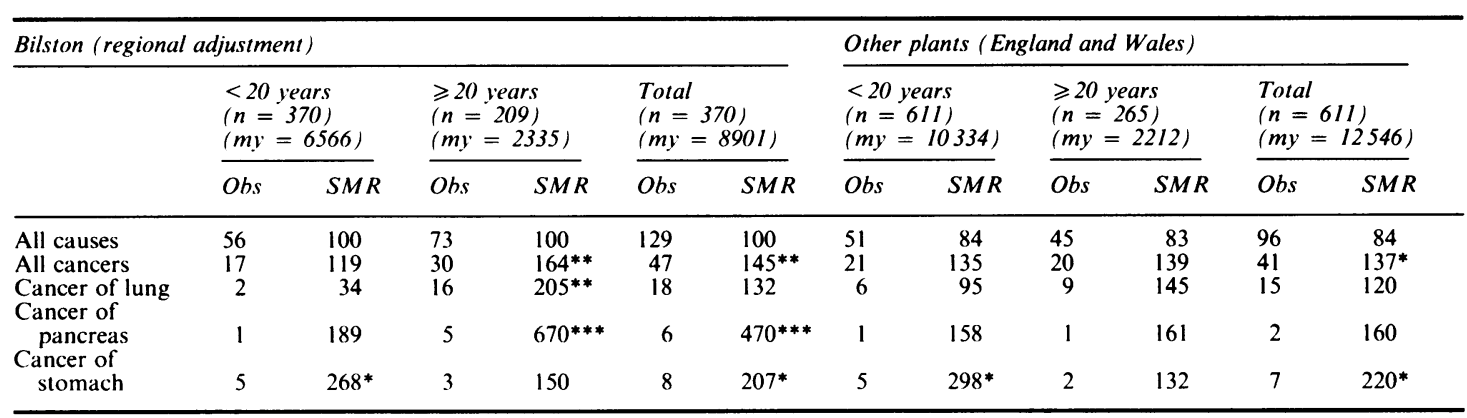

${ }^{*} \mathrm{p}<0.05 ;{ }^{* *} \mathrm{p}<0.01 ;{ }^{* * *} \mathrm{p}<0.005$

my $=$ Man-years. 
Table 7 Mortality of cylinder examiners at Bilston and other plants by duration of follow up

\begin{tabular}{|c|c|c|c|c|c|c|c|c|c|c|c|c|}
\hline \multicolumn{7}{|c|}{ Bilston (regional adjustment) } & \multicolumn{6}{|c|}{ Other plants (England and Wales) } \\
\hline & \multicolumn{2}{|c|}{$\begin{array}{l}<20 \text { years } \\
(n=39) \\
(m y=627)\end{array}$} & \multicolumn{2}{|c|}{$\begin{array}{l}\geqslant 20 \text { years } \\
(n=18) \\
(m y=183)\end{array}$} & \multicolumn{2}{|c|}{$\begin{array}{l}\text { Total } \\
(n=39) \\
(m y=810)\end{array}$} & \multicolumn{2}{|c|}{$\begin{array}{l}<20 \text { years } \\
(n=71) \\
(m y=1161)\end{array}$} & \multicolumn{2}{|c|}{$\begin{array}{l}\geqslant 20 \text { years } \\
(n=26) \\
(m y=199)\end{array}$} & \multicolumn{2}{|c|}{$\begin{array}{l}\text { Total } \\
(n=71) \\
(m y=1360)\end{array}$} \\
\hline & Obs & $S M R$ & Obs & $S M R$ & Obs & $S M R$ & Obs & $S M R$ & Obs & $S M R$ & Obs & $S M R$ \\
\hline $\begin{array}{l}\text { All causes } \\
\text { All cancers } \\
\text { Cancer of lung } \\
\text { Cancer of }\end{array}$ & $\begin{array}{r}12 \\
3 \\
1\end{array}$ & $\begin{array}{r}105 \\
101 \\
78\end{array}$ & $\begin{array}{r}11 \\
5 \\
3\end{array}$ & $\begin{array}{l}115 \\
234 \\
351\end{array}$ & $\begin{array}{r}23 \\
8 \\
4\end{array}$ & $\begin{array}{l}110 \\
157 \\
188\end{array}$ & $\begin{array}{l}8 \\
4 \\
1\end{array}$ & $\begin{array}{r}60 \\
113 \\
66\end{array}$ & $\begin{array}{l}3 \\
1 \\
1\end{array}$ & $\begin{array}{r}42 \\
59 \\
143\end{array}$ & $\begin{array}{r}11 \\
5 \\
2\end{array}$ & $\begin{array}{l}54 \\
95 \\
90\end{array}$ \\
\hline $\begin{array}{l}\text { pancreas } \\
\text { Cancer of }\end{array}$ & 0 & - & 2 & $2325^{* * *}$ & 2 & $1007^{*}$ & 1 & 672 & 0 & - & 1 & 451 \\
\hline stomach & 0 & - & 0 & - & 0 & - & 0 & - & 0 & - & 0 & - \\
\hline
\end{tabular}

${ }^{*} \mathrm{p}<0.05 ;{ }^{* *} \mathrm{p}<0.01 ;{ }^{* * *} \mathrm{p}<0.005$.

my $=$ Man-years.

Table 8 Mortality of $D A$ workers in Scotland

\begin{tabular}{lrrc}
\hline & \multicolumn{3}{l}{ Scotland } \\
\cline { 2 - 4 } & Obs & Exp & SMR \\
\hline All causes & 22 & $32 \cdot 3$ & 68 \\
Bronchitis & 3 & $1 \cdot 9$ & 159 \\
Pneumonia & 0 & $1 \cdot 2$ & - \\
All cancers & 10 & $7 \cdot 3$ & 137 \\
Cancer of lung & 5 & $3 \cdot 2$ & 155 \\
Cancer of pancreas & 0 & $0 \cdot 3$ & - \\
Cancer of stomach & 2 & $0 \cdot 7$ & 283 \\
\hline
\end{tabular}

year group there were 25 deaths at Bilston, SMR 110 , and seven in the other plants, SMR 112. Twelve of these deaths were due to cancer (8 lung cancer, 2 cancer of pancreas, 1 stomach cancer, 1 cancer of another site). The number of deaths in each five year period was small giving wide variations in SMR but no trend was noted with increasing duration of service.

There have been 22 deaths among the workers in Scotland (table 8). There were raised SMRs for bronchitis, cancer of the lung, and cancer of the stomach, showing the same trends as in England and Wales. No analysis was made of the small group in Northern Ireland.

\section{Cancer of the pancreas}

The most pronounced excess has been from cancer of the pancreas where eight deaths occurred, six of these in past workers at the Bilston plant when 1.3 would have been expected in the West Midlands conurbation and 2.0 in the other plants in England and Wales with 1.3 expected on the national figures. Three of these were among cylinder examiners, two of these at the Bilston plant.
The diagnosis of cancer of the pancreas is not an easy one because of the deep situation of the gland and its intimate relations with other organs in the abdomen. Confusion may arise between other locally occurring cancers and carcinoma of the body of the gland and between chronic pancreatitis and carcinoma of the head. In studies of asbestos workers pancreatic cancer has been confused with peritoneal mesothelioma. ${ }^{5}$ Care was therefore taken to validate the cause of death given on the death certificate. All eight cases were followed up to the hospital where the diagnosis was made and treatment given. Details are given in the appendix. In four necropsy confirmed the diagnosis and in two of these there was confirmatory histology. For three further patients a diagnosis of cancer of the head of the pancreas was made at operation. For one severely jaundiced man the diagnosis was made on purely clinical grounds.

One of the eight men had been employed for only four months, another for two years and seven months. The remainder had periods of employment of 10 years or longer. The latent period, the period between first employment and death, was over 20 years in six, and 19 and 16 years for the other two.

\section{Discussion}

The validity of this type of mortality study depends, firstly, on the availability of records of the population chosen for study and, secondly, on establishing the vital status of the population and the number and causes of death. We were assured that factories who had preserved their records had maintained and submitted a complete file and the trace rates were high both in England and Wales and in Scotland.

Because of the known use of crocidolite asbestos, the occurrence of mesothelioma might have been ex- 
pected but no death from this cause was recorded on any death certificate. The other notable feature is the excess of deaths due to cancer which is almost entirely due to cancers of the lung, pancreas, and stomach. The SMR for cancer of the lung was 132 at Bilston and 120 for the other plants. Even after making a regional adjustment for the West Midlands, the SMR remains significantly raised at Bilston in the long follow up group. Cancer of the lung is recognised as an asbestos related tumour, particularly in smokers, but has also been recognised as an occupational risk in the refining of nickel, in exposure to arsenic and chromates, to ionising radiation, and to such chemicals as chlor-methyl-ether.

There was a highly significant excess of deaths from cancer of the pancreas concentrated at Bilston. The special follow up of deaths from this cause was incomplete because histological material had been examined in only two cases. This is relevant because Selikoff reclassified 16 of 49 cancers of the pancreas in asbestos workers as peritoneal mesothelioma after histological examination. ${ }^{5}$

The mortality from cancer of the pancreas is rising; in the United States it is the fourth commonest cancer causing death. The subject has been well reviewed by Levinson. ${ }^{6}$ Racial and geographical features point to an environmental influence. Smoking, excess alcohol, and fat intake appear to be risk factors and an association with diabetes mellitus has also been found. A family has been reported in which four cases have occurred. Occupational causes have been suggested. Mancuso and El Attar found an excess mortality among workers exposed to 2-naphthylamine and benzidine. ${ }^{7}$ A study of chemists showed an excess mortality but no particular chemical was identified. ${ }^{8}$ Work in metal industries has been implicated by Dorken ${ }^{9}$ and Sparks and Wegman. ${ }^{10}$ Lin and Kessler have presented a multifactorial hypothesis that incriminated hydrocarbon exposure. ${ }^{11}$ This exposure may induce some forms of cytochromes P450 and through a sequence of interactions increase the production of oxygen radicals, or deplete oxygen quenchers. ${ }^{12}$ Among asbestos workers, gastrointestinal tumours may be increased, ${ }^{13}{ }^{14}$ but allowing for confusion in diagnosis between carcinoma of the pancreas and peritoneal mesothelioma, there is no firm evidence of an excess of pancreatic tumours. An investigation of mortality in San Francisco showed a significant relation between the asbestos content of drinking water and cancers of the gall bladder and pancreas in women ${ }^{15}$ but this was not confirmed in Connecticut. ${ }^{16}$

There is no apparent explanation of the significantly raised SMR for cancer of the stomach, particularly in those with shorter follow up. A recent study of workers producing calcium carbide showed an in- creased incidence of colonic and prostatic cancer but contributory regional geographical factors were probably involved. ${ }^{17}$

During the production of acetylene, exposures occurred historically to calcium carbide dust, which is irritant because of the action of moisture converting it to calcium oxide and calcium hydroxide.

Transient exposures also occur to trace quantities of phosphine, arsine, and ammonia, measurements of which show that all are below the exposure limits, arsine in particular being much below. It is not suggested that these exposures could have been influential.

The findings of this study are striking but evidence of an occupational factor influencing mortality from various cancers is conflicting. Deaths occurring predominantly after 20 years of follow up from first employment suggest that an occupational factor might be responsible; on the other hand, an equal or higher incidence of deaths from lung cancer and cancer of the stomach in workers with short periods of service does not support the presence of the dose response relation that is usually observed with industrial carcinogens. The concentrations of asbestos in the air shown by the simulation experiments are not high even in the earliest period between 1936 and 1939, and since 1939 individual exposures would have decreased steadily as the introduction of charcoal cylinders and then monolithic cylinders took place.

The figures suggest that cylinder examiners at Bilston may have been at particular risk but numbers are too small to draw definite conclusions. This highly industrial area of the West Midlands had many small workshops based on metal working and had a raised risk of cancer, ${ }^{3}$ but excesses of cancer persist in the study population even after adjustment for regional differences.

It is unfortunately not a feasible undertaking to review the cause of death in Bilston and its immediate locality.

The Bilston worker group is older than that in other plants and further observation would be of interest. The finding of a cluster of deaths from cancer of the pancreas is unexpected. As has been considered, the diagnosis is not always accurate; it may be a chance finding, it may be related to past conditions in the local environment and community, or it may be related to occupation. Confirmation of its significance will depend on similar findings in other occupational groups with similar exposures.

We thank the British Oxygen Company for their cooperation and for making their records available and the OPCS and DHSS for their careful tracing of this cohort. 


\section{Appendix}

\section{CANCER OF THE PANCREAS}

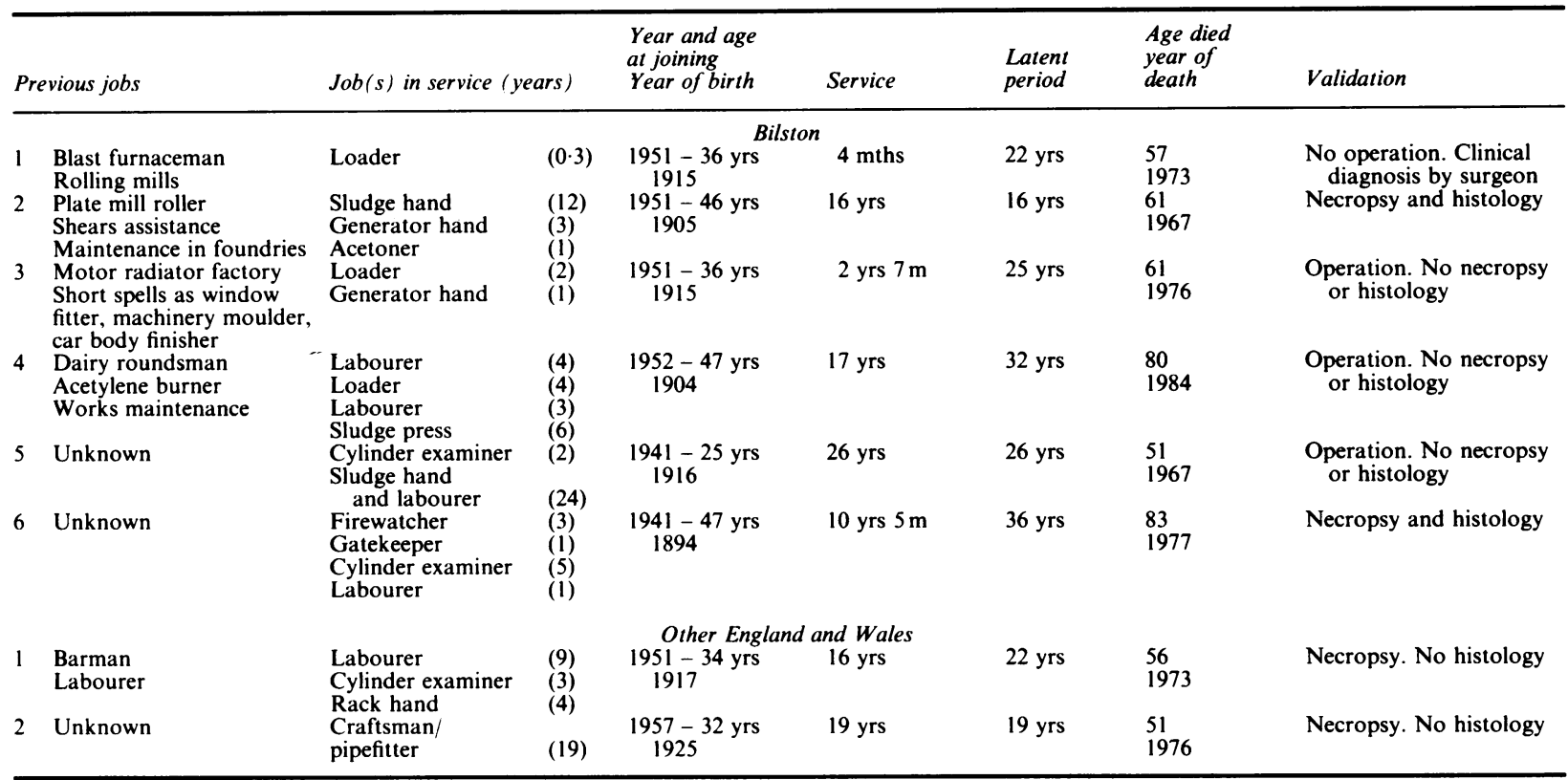

\section{References}

1 Asbestosis Research Council. Measurement of airborne asbestos dust by the membrane filter method. London: ARC, 1971. (Technical note No 1.)

2 Hill ID. Computing man years at risk. $\mathrm{Br} J$ Soc Prev Med 1972;26:132-4.

3 Gardner MJ, Winter PD, Taylor CP, Acheson ED. Atlas of cancer morlality in England and Wales 1968-78. Chichester: Wiley, 1983.

4 Office of Population Censuses and Surveys. Mortality statistics area England and Wales 1980-4. London: HMSO, 1982-5. (DH5 Nos 7-11.)

5 Selikoff LJ, Seidman H. Cancer of pancreas among asbestos insulation workers. Cancer 1981;suppl 47:1469-73.

6 Levinson DA. Carcinoma of the pancreas. J Pathol 1979:129:203-23.

7 Mancuso TF, El Attar AA. A cohort study of workers exposed to 2-naphthylamine and benzine. J Occup Med 1967:9:227-331.

$8 \mathrm{Li}$ FP. Fraumeni JF, Mantel N, Miller R. Cancer mortality among chemists. J Natl Cancer Inst 1969;43:1159-67.
9 Van Dorken H. Einige Daten bei 280 Patienten mit Pancreaskreb. Gastroenterologia 1964;102:47-77.

10 Sparks PJ, Wegman DH. Cause of death among jewellery workers. J Occup Med 1980;22:733-6.

11 Lin RS, Kessler I. A multifactorial model for pancreatic cancer in men. JAMA 1981;245:147-52.

12 Acheson DWK, Rose P, Shaw NP, Housten JB, Braganza JM. Induction of cytochrome P450 unifying factor in pancreatic disease. Gut 1984;25:A1142.

13 Newhouse ML, Berry G, Wagner JC. Mortality of factory workers in east London 1933-80. Br J Ind Med 1985;42:4-11.

14 Selikoff IJ. Asbestos disease in the United States. Revue Francais des Maladies Respetoires 1976;suppl 1:7-24.

15 Conforti PM, Kanarek MS, Jackson LA, Cooper RC, Murchio JC. Asbestos in drinking water and cancer in the San Francisco Bay area 1969-74. Incidence. J Chronic dis 1981;34:211-24.

16 Wister Meigs J, Walter SD, Hester JI, et al. Asbestos cement pipe and cancer in Connecticut 1955-74. J Environ Health 1980;4:187-91.

17 Kjuus $\mathbf{H}$, Andersen A, Langard S. Incidence of cancer among workers producing calcium carbide. $\mathrm{Br} J$ Ind Med 1986;245:147-52. 